\title{
Biopoder y eutanasia: aporía del paradigma inmunitario y potencialidad ético-política
}

Biopower and euthanasia: immune paradigm paradox and ethical-political potential

$\begin{array}{ll}\text { Nombre: } & \text { Francisco Marín Naritelli (1) } \\ \text { Filiación: } & \text { Universidad de Chile } \\ \text { País: } & \text { Chile } \\ \text { Correo: } & \text { hesse09@gmail.com }\end{array}$

\section{RESUMEN}

El presente ensayo busca reflexionar en torno a la eutanasia como un espacio de resistencia y simbolización frente a la sociedad contemporánea que deshumaniza la muerte y la desvía del espacio social compartido a partir de la utilización de los autores más representativos de la biopolítica moderna como Michael Foucault, Giorgio Agamben, Maurizio Lazzarato y Antonio Negri. Una de las conclusiones a las cuales se lograr llegar es que la eutanasia, más allá de las discusiones legales o morales, constituye un ejercicio biopolítico en el entendido que opera como una aporía del paradigma inmunitario que entroniza, precisamente, la asepsia y la prolongación técnica de la vida, al mismo tiempo que constituye una posibilidad ontopolítica de resignificación y autonomía de la propia libertad humana.

\section{ABSTRACT}

The following essay pretends to reflect on euthanasia as a space of resistance and symbolism facing the contemporary society that dehumanizes death and deviates it from the shared social space. The most representative authors of modern biolpolitics are used: Michel Foucault, Giorgio Agamben, Maurizio Lazzarato and Antonio Negri. One of the main conclusions achieved is that euthanasia, beyond legal or moral discussions, constitutes a biopolitical exercise in the sense that that it operates as a paradox of the immune paradigm, which precisely enthrones asepsis and artificial prolongation of life, while its constitutes, at the same time, an ontological possibility of resignification and autonomy of human liberty itself.

\footnotetext{
${ }^{1}$ El autor es Licenciado en Comunicación Social, Periodista de la Universidad de Chile. Actualmente cursa el Magister en Comunicación Política de la Universidad de Chile. Sus líneas de investigación son: Comunicación, biopolítica.
} 


\section{SEe}

PALABRAS CLAVES: Muerte, sociedad moderna, eutanasia, libertad, inmunidad.

KEYWORDS: Death, modern society, euthanasia, freedom, immunity.

\section{Introducción}

El viernes 17 de junio del presente año, el diputado de Renovación Nacional ${ }^{2}$, Gaspar Rivas, junto con su colega del Partido por la Democracia (PPD), Adriana Muñoz, ingresaron a la Cámara Baja un proyecto sobre eutanasia. Aunque no es la primera vez que un parlamentario envía una moción de estas características al Congreso Nacional de $\mathrm{Chile}^{3}$, sí es la primera de un congresista propiamente de derecha.

Según consigna el diario vespertino La Segunda, de propiedad del influyente empresario conservador, Agustín Edward, el parlamentario oficialista explica los alcances del proyecto de ley:

“Es un proyecto que permite que cuando una persona está sufriendo una enfermedad incurable, terminal o bien cuando ha sufrido un accidente que lo ha dejado en un estado que le produce un gran padecimiento, sufrimiento físico o psicológico que no tiene cura y que desea justamente poner término a su vida en forma voluntaria, pero no puede porque la enfermedad o el accidente lo ha dejado en un estado de incapacidad tal que no lo puede hacer, pueda solicitar la ayuda de un tercero, en este caso un médico autorizado que pueda practicar un procedimiento que acelere su proceso de muerte natural"4.

\footnotetext{
${ }^{2}$ Partido oficialista del Gobierno derechista del Presidente Sebastián Piñera.

${ }^{3}$ A la fecha se cuentan los siguientes proyectos en torno a la eutanasia: proyecto que regula la aplicación de la eutanasia en los casos que indica (octubre del 2004); moción que establece regulación legal de la eutanasia (mayo del 2006); proyecto de ley que establece el derecho a la muerte digna (junio del 2006) en primer trámite constitucional; proyecto de ley sobre derechos de los pacientes (junio del 2006) en primer trámite constitucional. Ver Biblioteca del Congreso Nacional.
}

4 La Segunda, edición online del 17 de junio de 2011 en <http://www.lasegunda.com/noticias/nacional/2011/06/656199/diputado-rn-defiende-suproyecto-de-eutanasia-la-vida-es-un-derecho-no-un-deber>. 


\section{SEe}

Dichos procedimientos, asegura Rivas, “deberán ser reconocidos como idóneos para tal efecto por la ciencia médica y deberán causar el menor sufrimiento al paciente, teniendo en consideración su dignidad humana" 5 .

Ahora bien, sea cual sea el destino normativo y legal (incluso moral) de tal proyecto, es interesante reconocer, en el sustrato mismo del presente argumento, o sea, en la eutanasia, una potencialidad política, una poiesis creadora, una avería que subvierte la lógica anestésica de la sociedad moderna, cuyo propósito teleológico es la superación de la muerte y el triunfo maquinal de la racionalidad técnica.

La eutanasia, más allá de su carácter marcadamente disyuntivo, desde el punto de vista de la legislación positiva, representa un espacio de significación y resignificación de la vida humana y su autonomía, por tanto, un ejercicio biopolitico. Sin embargo, antes de presentar los argumentos de dicho enunciado afirmativo, será necesario hacer un diagnóstico de la situación actual, entendiendo los desplazamientos y transformaciones del ethos social respecto a la vida y la muerte, esto es, la biopolítica. Para ello, utilizaremos la axiomática foucaultiana y los aportes posteriores respecto de los términos anteriormente reconocidos.

\section{Biopoder y sociedad inmunitaria}

Tentar una breve genealogía del biopoder, consiste principalmente en inspeccionar una tensión primera, y no menos problemática: la vida y la muerte, en el tejido mismo de la relación de fuerzas que se constituyen a partir de ellas. Entendiendo la naturaleza dinámica de dicho concepto, vale la pena reconocer un desplazamiento primordial, que inaugura todas aquellas técnicas, procedimientos y producciones respecto a aquello que llamamos vida, motivo y lugar, de las más hondas energías de subsunción, control y reproducción. Esto es, el camino progresivo de disponer de la vida hasta su protección en el contexto inmunitario de las sociedades occidentales.

Michael Foucault, en una perspectiva histórica, examina la naturaleza axiomática del derecho sobre la vida y la muerte, ante todo, como un derecho disimétrico, cuyo ejercicio deriva de las condiciones posibilitantes de uno y otro. El derecho como forma absoluta del poder soberano, se reconoce en la ratio representativa de la sociedad premoderna, como "instancia de deducción, mecanismo de sustracción, derecho de apropiarse de una parte de las riquezas, extorsión de productos, de bienes, de servicios, de trabajo y de sangre, impuesto a los súbditos de las cosas, del tiempo, los cuerpos y finalmente la vida; culminaba en el privilegio de apoderarse de ésta para suprimirla" (Foucault, 1998: 81). El poder sobre la vida (y la muerte), por tanto, obra como derecho de captación, que subsume

\footnotetext{
${ }^{5}$ Ibíd.
} 


\section{SEe}

la vida de los que están bajo ese poder, aniquilando los mecanismos y/o estrategias de resistencia o contra hegemonía.

Ahora bien, el reconocimiento de ese poder absoluto y soberano se verá desalojado de su condición cáustica, en la emergencia del corpus social de derecho, matriz de la sociedad disciplinaria. Para Negri y Hardt, "la puesta en marcha de esta sociedad, asegurando la obediencia a sus reglas y a sus mecanismos de inclusión y reclusión, es lograda a través de instituciones disciplinarias (la prisión, la fábrica, el asilo, el hospital, etc) que estructuran el terreno social y presentan lógicas adecuadas a la "razón" de la disciplina" (Negri, Hardt, 2000: 25). Se produce una transformación en la forma de concebir los mecanismos de poder, ya no desde el ámbito puramente coaptativo, sino en la organización de las fuerzas que somete, o sea, "un poder destinado a producir fuerzas, a hacerlas crecer y ordenarlas más que a obstaculizarlas, doblegarlas o destruirlas" (Foucault, 1998: 82). El poder sobre la vida y la muerte aparecerá limitado y relativo, reglamentado y sostenido en "el cuerpo social de asegurar la vida, mantenerla y desarrollarla" (Foucault, 1998: 82).

El nacimiento de la sociedad de control implica una nueva forma de concebir el desarrollo del biopoder. A la luz de los aportes de Antonio Negri es posible entender que "la más alta función de este poder es infiltrar cada vez más la vida, y su objetivo primario es administrar la vida. El biopoder, pues, se refiere a una situación en la cual el objetivo del poder es la producción y reproducción de la misma" (Negri, Hardt, 2000: 25). Entonces, el poder de hacer vivir o de rechazar el hacer la muerte reemplazará el centramiento del castigo punitivo y, en general, de todos los procedimientos disciplinarios a partir del poder estatal y sus controles reguladores respecto a la muerte. Se produce un decantamiento de sus lógicas de exhibición y se alerta una tendencia progresiva hacia su ocultamiento. De hecho, Philippe Ariès reconocerá aquí un profundo movimiento epistemológico en la forma de entender la muerte. Si antes el espacio de la muerte se constituía en "una figura familiar", el paso definitivo dentro del conjunto de vivencias del hombre, hoy solo "basta con nombrarla para provocar una tensión emotiva incompatible con el curso de la vida cotidiana" (Ariès: 2000: 211). La muerte no es la vida; es su opuesto absoluto y constituyente. Es enfermedad, peligro, consunción, no vida, lo que deviene en su borradura del espacio social, de su producción y reproducción. Hay un desalojo de sus ritos, y en general, de toda aproximación sucedánea en la forma en que Foucault reconoce como heterotopía desviada.

La desviación o dislocación del binario vida/muerte, también, acontece en la práctica sanitaria del enfermo o del presto a morir. Al respecto, Roberto Esposito identifica el "proceso general de superposición entre práctica terapéutica y ordenamiento político" (Esposito, 2005: 199) a partir de la siguiente premisa: "para devenir objeto de cuidado político, la vida debe ser separada y encerrada en 


\section{SEe}

espacios de progresiva desocialización que la inmunicen de toda deriva comunitaria" (Esposito, 2005: 199). Esta heterotopía desviada o desocialización tiene sus antecedentes en el sitial prominente que adquiere la higiene como control social, 0 sea, del avance de la medicina en general. Así lo describe Esposito:

“El primer paso es aislar los lugares en que puedendesarrollarse con mayor facilidad gérmenes infecciosos debidos a la acumulación de cuerpos, sean vivos o muertos: puertos, cárceles, fábricas, hospitales, cementerio. Pero todo territorio es subdividido de una manera gradual en zonas rígidamente separadas en función de una vigilancia a la vez médica y legal (...) con el paso del tiempo, a este modelo más arcaico se le superpone otro de derivación escolar y militar, tendiente, también, a la subdivisión espacial” (Esposito, 2005: 198).

La cuestión del desarrollo médico irá de la mano de una sistematicidad mayor. Esto es: una cierta tecnología del cuerpo social. La racionalidad biomédica o medicalización -cuyos antecedentes Foucault ${ }^{6}$ rastrea en el siglo XVIII- diagnostica la suspensión de la condición sacrificial verificada en el ser con otro, o sea, la potencialidad de la muerte. Algo así como una biohistoria, se ha constituido desde hace tres siglos, caracterizando "la existencia, la conducta, el comportamiento, el cuerpo humano en una red de medicalización cada vez más densa y más extensa, red que cuanto más funciona menos cosas deja fuera de control" (Foucault, 1999: 364). Tal como una vacuna hipodérmica, se constituye, en el paradigma capitalista, una “mecanización y la insensibilización del morir" (Duch, Mèlich, 2005: 307), dictando la protección de la vida a todo evento, a costa, incluso, del buen morir, desnaturalizado como destino de lo propiamente humano. Esta técnica anestésica cuyo objetivo en la configuración moderna, es la creación "de estados de insensibilización predecibles" (Brossat, 2008: 56)- elimina la manifestación rotunda de la contingencia, "de aquel conjunto de acontecimientos a los cuales todo ser humano, inexorablemente, se encuentra sometido" (Duch, Mèlich, 2005: 307). Es así como Giorgio Agamben destaca la ambición del biopoder moderno: "producir en un cuerpo humano la separación absoluta del viviente y del hablante, de la zoè y el bios, del no-hombre y del hombre: la supervivencia” (Agamben, 2002: 163).

El diagrama generativo de la sociedad actual supone e impone un nuevo acento representacional respecto a la vida y la muerte. En su certeza tecno-jurídica,

\footnotetext{
${ }^{6}$ Habrá que precisar que para Foucault, la medicina moderna nace como práctica social y solo en un aspecto es individualista y valora las relaciones entre el médico y el paciente. De hecho, con el capitalismo que se desarrolló a finales del siglo XVIII y comienzos del XIX, se masificó la medicina "colectiva" desde una medicina "privada".
} 


\section{SEe}

la deriva civilizatoria materializa la profunda asepsia, la supresión del dolor, del envejecimiento y la muerte. Alain Brossat atenderá a esta cuestión en referencia al carácter de la democracia contemporánea como un sistema de inmunidad, "donde las personas, los cuerpos, las opiniones, ven cómo establecen las condiciones de existencia y acceden a un estatus que los asegura y los garantiza" (Brossat, 2008: 8). Esto implica que los sujetos tienen la posibilidad de "existir" sin ser tocados, es decir, "sin ser objeto de aprensiones obligatorias o inhibitorias, de expectativas, de confiscaciones o de represalias por parte de una potencia, de una instancia o de una autoridad exterior" (Brossat, 2008: 8). Es en este sentido que la relación democraciainmunidad trama una operatoria de sustracción y de protección ${ }^{7}$, más que de expansión y creación como condición normativa. De esta forma, para Brossat "la invención democrática hallaría su forma determinante en estas operaciones de sustracción a los modos tradicionales de exposición a todo tipo de violencias, a las prerrogativas de los poderosos, a los caprichos y los apetitos de los poderes en funcionamiento" (Brossat, 2008: 9).

El término inmunidad es introducido por Roberto Esposito como antinomia dialéctica de conmunitas, o sea, la experiencia paradójica del hombre respecto a la comunidad. En tanto relación inmanente, conmunitas e inmunidad se establecen en el juego biopolítico como mecanismo afirmativo o refractario del ser común. Mientras uno apela a la comunión, el segundo lo hace a la sustracción. Mientras uno nunca comporta una propiedad o estadio de confinamiento sino un deber y una deuda (Nancy, 2000: 29), el segundo implica una liberación del riesgo. Dicho de otro modo: la especificidad del munus articula un don-a-dar, "un límite que se configura como un gravamen, o incluso una modalidad carencial, para quien está afectado (...) el sacrificio de la compensatio" (Esposito, 2003: 30). Por el contrario, la inmunitas implica "el beneficio de la dispensatio" (Esposito, 2003: 30). Así, la inmunidad se instituye como la exención de la carga, tributo o servicio "que un individuo le debe a un poder, a una potencia, a una institución" (Brossat, 2008: 10) en virtud de su protección normativa en el plexo de lo social. Paradójicamente antagónico, por tanto, a todo "sistema de reciprocidades, de interacciones y de entre-exposición de las singularidades" propias del ejercicio plenamente democrático, donde "cada uno se definirá ante todo, como el tributario de cada otro en particular y de todos en general (Brossat, 2008: 14).

Esposito entenderá la complejidad simbiótica entre lo político y el régimen de la vida respecto a la clausura de las condiciones posibilitantes del munus y el apresamiento de la singularidad somática: la intención inmunitaria consiste en demorar "cuanto se pueda el paso de la vida a la muerte, empujar la muerte al punto más alejado de la actualidad de la vida" (Esposito, 2005: 161). El cuerpo

\footnotetext{
${ }^{7}$ Brossat cita a Ernet Renat para referirse al carácter de la sociedad democrática en clave "negativa", pues entiende a la libertad como "facultad del no".
} 


\section{SEe}

inmunitario, entonces, es reconducido hacia la resistencia de todo orden que pretenda su cancelación, suspensión o amenaza. Es expropiado de su tendencia autodisolutiva por medio de su inmunización, pues el cuerpo "no es compatible con la muerte por mucho tiempo. Su encuentro es sólo momentáneo: muerto, el cuerpo no dura. Para ser cuerpo, debe mantenerse con vida” (Esposito, 2005: 161).

Desde una comprensión posestructuralista del biopoder, Deleuze y Guattari en palabras de Negri- ponen en evidencia la cuestión ontológica de la producción del ser social. Tal como las máquinas producen, los sujetos y los objetos también lo hacen. La nueva naturaleza del trabajo y su desarrollo viviente requieren del resguardo de la vida y la vigilancia de los cuerpos (Negri, Hardt, 2000: 30). Así se explica la portentosa maquinaria biopolítica, su radicalización y tecnificación a la par con la sociedad inmunitaria capitalista: “libertad de trabajo, pero es preciso asimismo que haya trabajadores, un número bastante grande de trabajadores, lo suficientemente competentes y calificados y que carezcan de armas políticas para que no puedan ejercer presión sobre el mercado laboral" (Foucault, 2007: 84). Esta racionalidad biopolítica -en el núcleo de la sociedad inmunitaria- "comprende, así, los dispositivos de poder que permiten maximizar la multiplicidad de las relaciones entre fuerzas que son coextensivas al cuerpo social, y no sólo, como en la economía política clásica y su crítica, la relación entre capital y trabajo” (Lazzarato: 2000).

De hecho, el mismo Foucault caracteriza las relaciones de poder en la sociedad contemporánea, donde es preciso ajustar el tiempo a las necesidades de la producción, y como segunda función, la transformación del cuerpo en fuerza de trabajo (Foucault: 2003). Del mismo modo, para Paolo Virno, comprender el nudo racional del término "biopolítica" implica pensar el concepto de fuerza de trabajo como "potencia para producir. Potencia, es decir, facultad, capacidad, dynamis (...) que es comprada por el capitalista, como una mercancía de excepcional importancia” (Virlo, 2003: 83). En tanto tal, el capitalismo transforma la potencia, la no-presencia en objetualidad, donde la vida del obrero importa por un motivo indirecto: "este cuerpo, esta vida, son aquello que contiene la facultad, la potencia, la dynamis. El cuerpo viviente se convierte en objeto a gobernar no tanto por su valor intrínseco, sino porque es el sustrato de la única cosa que verdaderamente importa: la fuerza de trabajo como suma de las más diversas facultades humanas" (Virlo, 2003: 85).

Es aquí donde la medicina ${ }^{8}$-como estrategia de poder- cumple un rol maquinal de mayor importe para el control de la vida: se yergue "como un instrumento de mantenimiento de renovación de la fuerza de trabajo para el funcionamiento de la sociedad moderna" (Foucault, 1999: 357). Pero no solo porque

\footnotetext{
${ }^{8}$ Para Foucault se pueden reconocer tres etapas de la formación de la medicina social: la medicina del Estado, la medicina urbana y la medicina de la fuerza de trabajo.
} 


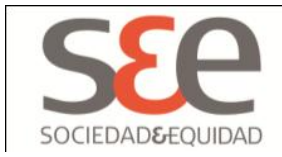

es capaz de reproducir la fuerza de trabajo, sino "porque puede producir directamente una riqueza, en la medida en que la salud representa un deseo para unos y un lujo para otros" (Foucault, 1999: 357). En este sentido, el cuerpo humano es una realidad biopolítica; la medicina es una estrategia biopolítica (Foucault, 1999: 366).

El biopoder moderno asume, en consecuencia, la condición de posibilidadpotencialidad de la vida de los cuerpos, su prolongación histérica y artificial en un continuum inexorable, al mismo tiempo que abre paso a la des-exposición de la muerte, su desplazamiento, su anonimato. Pero no solo la medicina social dicta la sentencia normalizadora en el campo de la funcionalidad económica, sino, también, el avance de las biotecnologías respecto a la propia naturaleza humana. A la salud como objeto de consumo habrá que sumar, ahora desde otra problematicidad, el peligro de la disponibilidad técnica de la programación eugenésica.

Dirá Habermas que hoy como nunca "se desvanece la frontera entre la naturaleza que "somos" y la dotación que nos “damos" (Habermas, 2004: 24). Siguiendo su argumento, "en las sociedades liberales serían los mercados los que, regidos por el interés en los beneficios y las preferencias de la demanda, pasarían la pelota de las decisiones eugenésicas a la elección individual de los padres, y, en general, a lo deseos anárquicos de clientes y clientelismos" (Habermas, 2004: 69).

La ley de la oferta y la demanda, la producción y reproducción social -en virtud del avance y desarrollo de las biotecnologías- tecnifican las posibilidades y amplían el horizonte de la naturaleza humana, ya sea en la prolongación de la vida como en la intervención genética. Esto representa un serio desafío a la libertad y la igualdad humana, pues en el momento en que se instaura ese "umbral de modernidad biológica" (Foucault, 1998: 85) -como lo denomina Foucault, también en una perspectiva habermasiana, donde es la propia especie que "entra como apuesta del juego en sus propias estrategias políticas"- se corre el riesgo de poner "en entredicho su vida de ser viviente" (Foucault, 1998: 85).

Frente a esta problemática, surge la eutanasia como una aporía del contexto inmunológico que permite, de alguna forma, restituir en el sujeto la responsabilidad de su vida como autor indiviso e inalienable de su propia existencia. Habrá que precisar, eso sí, qué entendemos por eutanasia, también en su deriva epistemológica, para luego examinar su potencialidad política dentro de la autocomprensión humana. 


\section{SSe}

\section{Aproximaciones al término eutanasia}

El término "eutanasia" se compone de dos palabras griegas -eu y thanatos- que significan, literalmente, «buena muerte» (Kuhse: 2004). Para Pedro Eva Condemarín", la eutanasia, en su aceptación predominante, es "la acción u omisión que permite, acelera o provoca la muerte de un paciente terminal para evitar sus sufrimientos" (Eva Condemarín: 1998). El concepto de eutanasia" ${ }^{10}$ presume "la intervención de un agente distinto del enfermo y que ella se lleve a cabo por el bien de éste, movida por la compasión" (Eva Condemarín: 1998).

En palabras de Helga Kuhse, el término eutanasia implica dos actos ineludibles: "en primer lugar, que la eutanasia supone acabar deliberadamente con la vida de una persona; $y$, en segundo lugar, que esto se lleva a cabo por el bien de la persona de cuya vida se trata -normalmente porque padece una enfermedad incurable o terminal. Esto distingue a la eutanasia de la mayoría de las demás formas de quitar la vida" (Kuhse: 2004). Ahora bien, tomando la precaución de Kuhse, es loable preguntarse “¿Es moralmente significativa la distinción entre matar o dejar morir, o entre eutanasia activa y pasiva? ¿Es siempre moralmente peor matar a una persona que dejar morir a una persona?"(Kuhse: 2004).

Para ello será relevante distinguir entre acción y omisión ${ }^{11}$. Matar a una persona es una acción, y dejar morir a alguien se constituye en una omisión. Aplicando esta nomenclatura a los actos de eutanasia, reconoceremos la eutanasia activa o pasiva. Si la primera apunta a la muerte de un paciente producto de la intervención directa de un tercero, la segunda alude a la omisión de aquellos procedimientos médicos destinados a preservar la vida de un paciente. La significación moral de dicha distinción, muchas veces, trae consigo una avería conceptual.

\footnotetext{
9 Médico Psiquiatra, Profesor Asistente del Departamento de Psiquiatría y Salud Mental, Facultad de Medicina, Universidad de Chile.

${ }^{10}$ Eva Condemarín reconoce las siguientes clasificaciones existentes entorno a la eutanasia:

"Eutanasia voluntaria, la decisión la toma el paciente directamente o terceros obedeciendo los deseos que el paciente ha expresado con anterioridad; eutanasia no voluntaria, la decisión la toma un tercero sin que haya habido posibilidades de conocer la determinación del enfermo; eutanasia involuntaria, la decisión la toma un tercero sin pedir el consentimiento de un paciente capaz de expresar su elección o en contra de su voluntad; eutanasia activa (o positiva): por acción (administración de sustancia letal p.e.); eutanasia pasiva (o negativa): por omisión (abstención o retiro de terapias) y eutanasia directa: la acción u omisión intenta la muerte del paciente" (Eva Condemarín: 1998).

${ }^{11}$ El presente trabajo no pretende hacer un análisis sintáctico de las diferentes formas de eutanasia, así como de sus precauciones y variables existentes, sino que, de manera genérica, presenta el argumento pretendido para defender la tesis expuesta.
} 


\section{SEe}

Matar/dejar morir supone, en la perspectiva teológica, una cierta valoración de lo que es la vida y lo que es la muerte. Dejar morir o provocar la muerte sería "irrevocablemente malo", pues el sentido de la vida es su conservación. Lo bueno sería vivir y lo malo sería morir. Esta sentencia es atendible en un contexto de "normalidad de la existencia"; sin embargo, la eutanasia implica necesariamente una inversión de los términos.

En una situación de padecimiento producto de una enfermad incurable, donde generalmente se invoca la eutanasia, "el mejor interés de una persona es morir y no seguir con vida. Esto quiere decir que un agente que mata, o un agente que deja morir, no está dañando sino beneficiando a la persona de cuya vida se trata" (Kuhse: 2004).

En ningún caso se plantea alguna acción tendiente a privar de vida a aquel que no lo ha manifestado. Esta diferencia es central, pues, aún cuando sea atendible la eutanasia involuntaria o no voluntaria (en el caso de la decisión de un tercero sin el consentimiento del paciente y de la disposición de recién nacidos malformados). Para efectos del presente trabajo, solo un tipo de eutanasia es susceptible de reconocerse como potencialidad política ${ }^{12}$. Descartando de plano aquel acto de eutanasia que no cuente con la manifestación de voluntad del paciente, entendemos el concepto, en su deriva voluntaria, activa o pasiva, en virtud de la autonomía de la voluntad y la calidad de la vida del paciente, tal como refiere Helga Kuhse. Al respecto, frente "a la santidad de la vida" se plantea la evaluación de la calidad de vida del paciente "como una variable determinante a la hora de la toma de decisiones" (Eva Condemarín: 1998). Desde esta perspectiva, "las decisiones basadas en la calidad de vida deberían considerar a toda persona de igual valor, deberían diferenciar entre una vida personal y una vida meramente biológica, deberían ser tomadas por el propio enfermo o por quien pueda defender sus mejores intereses y deberían reconocer que para el paciente no toda forma de vida tiene igual valor" (Eva Condemarín: 1998).

\section{Perspectivas, aciertos y desaciertos}

La legislación positiva, o sea, el corpus normativo-jurídico que rige nuestro país, rechaza cualquier intervención, activa o pasiva, que atente "contra la vida" en todas sus formas. Incluso, la pena de muerte, está cuidadosamente restringida y "solo podrá establecerse por delito contemplado en ley aprobada por quórum calificado"13. Es así como en el artículo 19, número $1^{\circ}$, de la Constitución Política de 1980,

\footnotetext{
${ }^{12}$ Desde este momento, las argumentaciones ulteriores supondrán la eutanasia según su deriva voluntaria, activa y pasiva.

${ }^{13}$ Biblioteca del Congreso Nacional en <http://www.bcn.cl/lc/cpolitica/index_html>
} 


\section{SEe}

reconoce a todas las personas el derecho a la vida y a la integridad física y psíquica, así como en su inciso posterior, protege la vida del que está por nacer ${ }^{14}$.

Las huellas del paradigma inmunitario se encuentran en el sustrato mismo de dicha legislación al consagrar todavía -en una cosmovisión metafísica- el derecho a la vida como un derecho natural, inalienable ni usurpable por ningún Estado o régimen punitivo. Tal como reconocen Foucault y Esposito, los cuerpos materiales de los individuos, como el lugar privilegiado para la vida, "todos y cada uno, son los que deben ser cuidados, estimulados, multiplicados como el bien absoluto del cual el Estado deriva su propia legitimación" (Esposito, 2005: 194). En otras palabras, “el Estado no existe por fuera de los cuerpos de los individuos que lo integran" (Esposito, 2005: 194).

De hecho, José Joaquín Ugarte Godoy ${ }^{15}$, sostiene que para comprender los alcances de la norma constitucional, se requiere un paso previo: reconocer el ethos teológico fundante en la tradición católica. El derecho a la vida consagrado en la Constitución "es un derecho natural y obra de Dios, que se tiene por el solo hecho de ser persona, y que consiste en el derecho de mantener la vida o conservarla frente a los demás hombres, o si se quiere, en el derecho a que nadie nos la quite, y a que no pueda suprimirla ni cercenarla ni siquiera su propio sujeto” (Ugarte Godoy: 2006).

La anterior definición reitera la inconstitucionalidad de prácticas que contravengan el principio absoluto "y sacro" de la vida consagrada en la legislación, doctrina y jurisprudencia nacional, independiente de sus diversos (y hasta disímiles) orígenes epistemológicos: desde el homicidio hasta el aborto, suicidio, eutanasia o eugenesia. Bajo este entendido, la vida humana se constituye como extensión divina, la cual decide por su obra directa, disponiendo de sus alcances y finitud:

"El derecho a la vida se basa en que la persona humana, sin perjuicio de su radical ordenación a Dios, es un cierto fin en sí, pues por su razón e inteligencia puede poseerse a sí misma mediante el conocimiento, y a los demás seres, e incluso de alguna manera a Dios; y mediante su voluntad libre, puede amar a Dios, y a sí mismo y al prójimo, y tiene dominio de sus actos, pudiendo ordenarlos a su propio bien; de todo lo cual se sigue que el hombre tiene una cierta autodestinación y una cierta interioridad" (Ugarte Godoy; 2006: 515).

\footnotetext{
${ }^{14}$ Ibíd.

${ }^{15}$ Profesor de Derecho Civil y Filosofía del Derecho en la Pontificia Universidad Católica de Chile.
} 


\section{S\&e}

La vida es indisponible para los propios sujetos; sus cuerpos son obras indisponibles de aquello que es anterior a ellos: están por fuera de su autonomía y comprensión. Cualquier intento destinado a terminar con esa indisposición caería inevitablemente- en una práctica que contraviene el deber ser de una sociedad moral. El acto de transgresión de dicho precepto, por tanto, no solo violenta la normativa legal existente, sino también el carácter de lo humano como dominio de Dios.

La eutanasia aparece como una infracción anti natura a la dignidad humana, "una conducta intrínsecamente mala que ninguna causa puede justificar" (Ugarte Godoy: 2006). Sin embargo, tal como consigna el proyecto de ley del diputado Rivas, es posible instalar un cierto principio ético de autonomía de la voluntad, o sea, o reconocer, proteger o amparar a todos los ciudadanos el deber de vivir su vida" ${ }^{16}$. Esto abre una serie de interrogantes, en especial en torno a la comprensión de lo que entendemos por vida, y también de lo que entendemos por muerte más allá de las exigencias de una interpretación inmunitaria -ya sea en su deriva metafísica como en su dimensión técnica-.

\section{¿Autonomía de la voluntad.... ejercicio de la libertad?}

Si para Aristóteles el hombre es un animal viviente capaz de una existencia política, de bíos políticos, para efectos del presente trabajo, la muerte como conciencia individual y social-, también es régimen de politicidad, más aún respecto a la disposición de la propia vida. Pero, ¿qué entendemos por conciencia de la muerte?, y más aún, ¿qué implicancias posee una conciencia de la muerte para el campo de la libertad y la dignidad humana?

Martín Heidegger reconocerá en el sujeto, desde una ontología posmetafísica, un "ser para la muerte" (Duch, Mèlich, 2005: 333), donde la muerte es la huella inefable del ser en el mundo. Desde la psicología analítica, en cambio, la conciencia de la muerte constituye "la experiencia preliminar del ser humano" (Carretero Gramage: 2004), en la cual, el sujeto, al asumir previamente el límite vida/muerte, "moldea sus aspiraciones, lo que lo propulsa de manera sorprendente hacia una visión personal de sus inquietudes, acercándolo hacia cotas imprevistas de realización subjetiva y objetiva" (Carretero Gramage: 2004).

La conciencia de la muerte, como horizonte de sentido de la propia existencia, determina una producción onto-política constitutiva de la libertad primera del sujeto acontecimental. Es lo que Lluis Duch y Joan-Carles Mèlich (2005) llamarán una reconquista humanista. Para ello habrá que desligarse de toda atadura

\footnotetext{
${ }^{16}$ <http://www.lasegunda.com/noticias/nacional/2011/06/656199/diputado-rn-defiende-suproyecto-de-eutanasia-la-vida-es-un-derecho-no-un-deber>.
} 


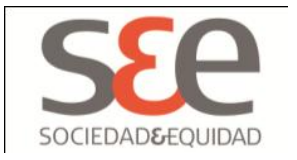

teológica (o apriorística), para desacralizar la vida como trasfondo metafísico. Habermas, ya lo explica cuando retruca al supuesto carácter ontológico del nonato: recién cuando el feto nace es constitutivo de derechos, desde ese momento asume la condición de ser humano afecto a un reconocimiento recíproco y vinculante. Solo en la comunidad política y ética el sujeto es inviolable; empero, hay que hacer una salvedad. En torno a esto, precisaremos el argumento habermasiano, para conservar su axiomática primordial.

En una visión algo antojadiza del planteamiento de Habermas, se podría llegar a conjeturar (y aventurar) dos argumentos potencialmente catastróficos:

a)

Que si el sujeto es inviolable en el momento de su nacimiento, esta inviolabilidad asume una condición absoluta.

b) Que tal como la eugenesia liberal -denunciada por Habermassupone el derecho de los padres a elegir la disposición genética de sus hijos, esto es inmediatamente asimilable al derecho de los sujetos a disponer de su propia vida.

Una metafísica en torno a la vida y la muerte en una sociedad cosmovisivamente pluralista derivaría en la imposibilidad cierta (legal y moral) de la eutanasia. Sin embargo, una ética de la especie, a juicio de Habermas, siempre implica la autocomprensión del ser radicada en la misma comunidad moral. Es en ella en que se obliga y se expresa lo humano. Esto significa un ejercicio democrático de la voluntad, no inherente al sujeto sino a su potencialidad. Por lo tanto, "la auto comprensión ética ni es revelada ni dada de cualquier manera. Sólo puede ganarse en un esfuerzo común" (Habermas, 2004: 23).

Se hace extensible y comprensible, entonces, el llamado a la prudencia que realiza Lolas al reconocer el lazo constitutivo entre individualidad y muerte, entre comunidad y muerte. Una bioética, a juicio del autor, debe considerar -más allá de los formalismos instrumentales- el carácter endogámico del morir como práctica alojada socialmente, pues "las formas de morir son tan propias de una sociedad como las de vivir"(Lolas Stepke: 1997). En tal sentido, los dilemas universales y perennes asociados a la muerte y el morir requieren de "la reciprocidad y la solidaridad que surgen de una comunidad de hablantes que articulan sus discursos en el medio de la comunicación y del lenguaje, y que son capaces de disentir y criticar con respeto y en un clima de humana dignidad” (Lolas Stepke: 1997).

¿Acaso el afecto a una dolencia tan devastadora no tiene derecho a disponer de su propia vida por mandato de su propia dignidad? ¿Acaso en nombre de la vida podemos rechazar la muerte digna de quien no desea vivir? 


\section{SEe}

Tal como la manipulación genética "afecta a cuestiones de identidad de la especie, y la auto comprensión del ser humano" (Habermas, 2004: 37), la disponibilidad técnica de la vida reproduce el más recalcitrante paternalismo en pos de su prolongación artificial. La eugenesia liberal propugna lo inverso a la eutanasia.

Ahora bien, no se puede ignorar el espacio disyuntivo que recae en una defensa de la eutanasia, pero, a la vez, no es dado ni lícito ignorar la distancia epistemológica que hay entre eugenesia y eutanasia. No se puede equiparar posibilidad de manipulación del propio sustrato genético, incluso la indisponibilidad ${ }^{17}$ del feto respecto a su vida futura, a la disposición del propio sujeto respecto a su vida presente. La autoridad recae precisa e inalienablemente en el sujeto (social e individual) y no en la preferencia originada en el poder adquisitivo o en cierta operatoria o modulación técnica.

El sujeto debe estar "individualizado y regido por sí mismo" (Habermas, 2004: 46) dirá Habermas; por tanto, la inviolabilidad de la persona no colinda con la disposición de la vida en ningún caso. Al parecer, este es el fundamento teórico que subyace en el planteamiento del diputado Rivas, pues "la decisión de terminar con la vida es potestad inalienable del propio afectado"18, reconocido como un "derecho personalísimo y como tal le compete sólo al titular, al afectado mismo su disposición y si lo mantiene o si renuncia a su derecho"19.

Desalojado de toda pretensión metafísica y teológica, el ser si mismo, se aleja de la indistinción eutanasia y eugenesia. Entonces, contrario a los cuestionamientos que dictan alguna relación entre estos dos conceptos derivados de una posible confusión conceptual, la eutanasia es, en último término, el ejercicio más pleno de esa autocomprensión.

A modo de precaución se dirá que, en ningún caso, se envalentona la práctica de la eutanasia como ejercicio autoexpresivo de excreción social, sino más bien la exposición de una conciencia crítica. El derecho a la muerte digna, en condiciones claramente prescriptibles por el corpus social, a nuestro juicio, representa un espacio de acción política, que implica una moralización de la naturaleza humana. Esto es, el hombre -en tanto ser ahí, junto a otros- que asume su cuerpo, como un espacio de tránsitos y luchas, de vida y muerte, "de concreción propia, identificadora e identificante de la presencia corporal del ser humano en su mundo"

\footnotetext{
${ }^{17}$ Habermas reconoce la indisponibilidad del feto para su manipulación mercantil, aunque no tenga el status de sujeto de acción, portador de derechos y deberes en el seno de la comunidad social. Esto es: lo propiamente inviolable.

18 <http://www.lasegunda.com/noticias/nacional/2011/06/656199/diputado-rn-defiende-suproyecto-de-eutanasia-la-vida-es-un-derecho-no-un-deber>

${ }^{19}$ Ibíd.
} 


\section{S\&e \\ socenemo}

(Duch, Mèlich, 2005: 240), pues, ¿acaso el mero cuerpo como nuda zoè es el claustro del cual el hombre jamás podrá escapar?; ¿quién más merece verse restituido en su acción que el hombre al disponer de su vida?

La acción es intensamente personal, decía Arendt, pues "la acción sin un nombre, un quién ligado a ella, carece de significado" (Arendt, 1995: 104). Pero la acción también produce historias, raigambre, impredecibilidad, porque "donde quiera que los hombres viven juntos, existe una trama de relaciones humanas que está, por así decirlo, urdida por los actos y las palabras de innumerables personas, tanto vivas como muertas" (Arendt, 1995: 105). Entonces, contrario a los dictados del phármakon ${ }^{20}$, del alivio que calma, del regocijo anestésico; más allá de la inmunidad propendida como pura negatividad del ejercicio del poder, que condiciona toda forma de subjetivación y resistencia, la eutanasia, en alguna de sus formas, se constituye en un acto de aclamación, dislocación y aporía de esa mutación civilizadora. Al menos, un comienzo de restitución del bios, camino que aguarda y no resguarda, que inquieta y no aquieta. Es la condena propositiva, la apertura ontológica, "el recordatorio siempre presente de que los hombres, aunque han de morir, no han nacido para eso, sino para comenzar algo nuevo" (Arendt, 1995: 107). En definitiva, una posibilidad trascendental de libertad y humanidad para la propia existencia del ser humano.

\section{Referencias bibliográficas}

Agamben, Giorgio (2002). Lo que queda de Auschwitz.Valencia: Ed. Pre-textos. Traducción de Antonio Gimeno Cuspinera en Arancibia, Juan Pablo (2011). El Mito de la Democracia: Apuntes Filosóficos-Políticos sobre el Orden Demoliberal en Tiempos de Bicentenario. Escrituras del Malestar. Chile del Bicentenario. Universidad de Chile, Santiago.

Arendt, Hannah (1995). De la historia a la acción. Barcelona: Paidós.

Ariès, Philippe (2000). Morir en Occidente. Desde la Edad Media hasta la actualidad. Buenos Aires: Filosofía e historia. AH.

Brossat, Alain (2008). La democracia inmunitaria. Santiago: Colección Contratiempo, Palinodia.

\footnotetext{
${ }^{20}$ Esposito identifica el carácter binario del concepto de phármakon en su genealogía histórica: mal y antídoto, veneno y cura, poción y contraposición.
} 


\section{s\&e \\ SOCIEDADEEQUIDAD}

Constitución Política de la República de Chile. Biblioteca del Congreso Nacional de Chile. Recuperado de <http://www.bcn.cl/lc/cpolitica/index_html>

Carretero Gramage, Ricardo (2004). La individuación y la muerte: Variaciones sobre la tragedia. Conferencia presentada durante el Congreso Internacional de Psicología Analítica en Barcelona, España. Agosto-septiembre de 2004. Recuperado de <http://www.adepac.org/P06-14.htm>

Duch, Lluis y Mèlich, Joan-Carles (2005). Escenarios de la Corporeidad. Antropología de la vida cotidiana. Madrid: Editorial Trotta.

Esposito, Roberto (2005). Immutinas. Protección y negación de la vida. Buenos Aires: Amorrortu/editores.

Esposito, Roberto (2003). Communitas. Origen y destino de la comunidad. Buenos Aires: Amorrortu/editores.

Eva Condemarín, Pedro(1998). Eutanasia . Anales de la Universidad de Chile. Recuperado de <http://www.revistas.uchile.cl/index.php/ANUC/article/viewPDFInterstitial/2039/1 887>

Foucault, Michael (2007). Nacimiento de la Biopolítica. Buenos Aires: Fondo de Cultura Económica.

Foucault, Michael (2003). La inclusión forzada: el secuestro institucional del cuerpo y el tiempo persona en La Verdad y las Formas Jurídicas. Barcelona: Editorial Gedisa. Conferencias pronunciadas en mayo de 1973 en la Pontificia Universidad Católica de Río de Janeiro. Traducción de Enrique Lynch. p.15.

Foucault, Michael (1999). ¿Crisis de la medicina o crisis de la antimedicina? en Estrategias de poder. Obras Esenciales, volumen II. Barcelona: Paidós.

Foucault, Michael (1999). El nacimiento de la medicina social en Estrategias de poder. Obras Esenciales, volumen II. Barcelona: Paidós.

Foucault, Michael (1998). Historia de la Sexualidad. Madrid: Siglo XXI editores. 


\section{S\&e}

Habermas, Jürgen (2004). El futuro de la naturaleza humana ¿Hacia una eugenesia liberal? Buenos Aires: Paidós.

Kuhse, Helga (2004). La eutanasia. Traducción de Jorge Vigil Rubio en Singer, Peter (ed.). Compendio de ética. Madrid: Alianza Editorial.

Lazzarato, Maurizio (2000). Del Bipoder a la Biopolítica. Revista Multitudes: Recuperado de <http://www.sindominio.net/arkitzean/otrascosas/lazzarato.htm>

Lolas Stepke, Fernando (1997). La muerte es tema para los vivos: Una perspectiva socioética. Anales de la Universidad de Chile. Sexta serie, $\mathrm{N}^{\circ} 6$. Recuperado de: <http://www.anales.uchile.cl/6s/n6/est5.html>.

Nancy, Jean-Luc (1999). Conloquium en Esposito, Roberto (2003). Communitas. Origen y destino de la comunidad. Buenos Aires: Amorrortu/editores.

Negri, Antonio y Hardt, Michael (2000). Imperio. Massachussets: Harvard University Press Cambridge.

Ugarte Godoy y José Joaquín (2006). El Derecho a La Vida y La Constitución. Revista Chilena de Derecho. v.33 n.3 Santiago. Recuperada de <http: //www.scielo.cl/scielo.php?pid=S0718-34372006000300004\&script=sci_arttext > Virno, Paolo (2003). Gramática de la Multitud. Madrid: Edición Traficantes de Sueños. 